\title{
ИССЛЕДОВАНИЕ ПРОЦЕССА ТЕРМИЧЕСКОЙ ДИССОЦИАЦИИ ПЕНТАХЛОРИДА ТАНТАЛА В ВАКУУМЕ
}

\author{
Ю.И. Поляков, С.Г. Руденький, Ю.В. Лукирский, И.И. Коновалов, В.И. Рак \\ Национальный научный центр «Харьковский физико-технический институт», \\ Харьков, Украина \\ Тел. (057)335-67-82
}

В рамках равновесной химической термодинамики получена зависимость степени диссоциации паров $\mathrm{TaCl}_{5} \alpha(T, P)$ от температуры в интервале $1470 \ldots 1820$ К и вакууме $1,33 \cdot 10^{-2}$ Па. Проанализированы и сравниваются расчетные данные с экспериментальными данными зависимости $\alpha_{\text {экп }}(T, P)$ от температуры и массового потока паров $\mathrm{TaCl}_{5}$.

\section{ВВЕДЕНИЕ}

Цель работы - исследование процесса термической диссоциации паров пентахлорида тантала в интервале температур $1470 \ldots 1820$ K и проточной вакуумной системе, ориентированное на достижение возможности получения покрытий Та толщиной $\geq 250$ мкм в виде герметичной коррозионно-стойкой оболочки в условиях облучения высокоэнергетичными электронами в водной среде на вольфрамовых пластинах размером $66 \times 66 \times 3 ; 4 ; 6 ; 10$ мм, являющихся нейтронообразующими элементами мишени установки «Источник нейтронов».

\section{1. РАВНОВЕСНАЯ ХИМИЧЕСКАЯ ТЕРМОДИНАМИКА ТЕРМИЧЕСКОЙ ДИССОЦИАЦИИ $\mathbf{T a C l}_{5}$}

Общие вопросы получения твердофазных конденсатов осаждением из газовой фазы методом CVD изложены в монографии [1]. Частный случай кинетики гетерогенных обратимых реакций типа $\mathrm{A} \leftrightarrow \mathrm{vB}$ рассмотрен в работе [2]. В конкретном случае осаждение тантала из паров пентахлорида производится в проточной вакуумной системе (в отличие от метода Ван Аркеля-Де Бура, реализуемого в замкнутом объеме).

Отметим, что именно применение вакуумных условий при термодиссациации $\mathrm{TaCl}_{5}$ позволяет осуществить осаждение танталовых покрытий с наблюдаемой скоростью. Пониженное давление способствует увеличению степени превращения для реакций, протекающих с увеличением числа частиц в газовой фазе в соответствии с принципом ЛеШателье. Именно использование вакуума позволяет осуществить процесс термической диссоциации $\mathrm{TaCl}_{5}$ с целью получения твердого тантала.

Параметры технологического процесса (температура подложки, давление вблизи поверхности роста конденсата, удельный массовый поток паров пентахлорида) задают скорость осаждения (травления) тантала, а также структуру и свойства покрытия. Термодинамические расчеты равновесия используемой химической реакции позволяют оценить диапазон изменения технологических параметров для результативного процесса, а сравнение с экспериментальными данными - оптимизировать условия осаждения с точки зрения получения покрытий с заданными свойствами.

\section{Скорость осаждения тантала}

$$
V_{\mathrm{Ta}}=\beta \alpha_{\mathrm{TaCl}_{5}(P, t)} \frac{\Delta m_{\mathrm{TaCl}_{5}}}{\Delta t \rho_{\mathrm{Ta}} S} \cdot \frac{\mathrm{A}_{\mathrm{Ta}}}{\mathrm{M}_{\mathrm{TaCl}_{5}}},
$$

где $\beta$ - коэффициент, зависящий от геометрии реактора (устанавливается эмпирически); $\alpha_{\mathrm{TaCl}_{5}(P, t)}$ равновесная степень превращения $\mathrm{TaCl}_{5}$ при давлении $P$ (атм) и температуре осаждения $T ; \Delta m_{\mathrm{TaCl}_{5}}-$ масса $\mathrm{TaCl}_{5}$, поданного к поверхности площадью $S$ за время $\Delta t ; \rho_{\mathrm{Ta}}-$ плотность Та; $\mathrm{A}_{\mathrm{Ta}}-$ атомный вес Та; $\mathrm{M}_{\mathrm{TaCl}_{5}}$ - молекулярный вес $\mathrm{TaCl}_{5}$.

$$
\begin{aligned}
& \text { Для реакции } \\
& \mathrm{TaCl}_{5}(\text { газ) } \leftrightarrow \mathrm{Ta}(\text { тв.) }+5 \mathrm{Cl} \text { (газ), }
\end{aligned}
$$

протекающей в равновесных условиях, величина $\alpha$ определяется соотношением

$$
\mathrm{K}_{\rho}=5^{5} \alpha^{5} P^{4} /(1-\alpha)(1+4 \alpha),
$$

где $\mathrm{K}_{\rho}$ - константа равновесия:

$$
\mathrm{K}_{\rho}=\frac{P_{\mathrm{Cl}}^{5}}{P_{\mathrm{TaCl}_{5}}} \times a_{\mathrm{Ta}},
$$

a $P_{\mathrm{Cl}}, P_{\mathrm{TaCl}_{5}}$ - парциальные давления $\mathrm{Cl}$ и $\mathrm{TaCl}_{5}$, $a_{\mathrm{Ta}}-$ активность тантала равна 1 .

Константа равновесия $\mathrm{K}_{\rho}$ связана с изменением свободной энергии Гиббса в результате протекания реакции по уравнению Гиббса-Гельмгольца (энтропийное приближение, $\left.\Delta C_{\rho}=0\right)$ :

$$
\Delta G_{\text {реакц }}=\Delta \mathrm{H}_{298}^{\text {реакц }}-T \Delta S_{298}^{\text {реакц }},
$$

где $\Delta \mathrm{H}_{298}^{\text {реакц }} \Delta S_{298}^{\text {реакц }}-$ изменение энтальпии и энтропии соответственно:

$$
\begin{aligned}
& \Delta \mathrm{H}_{298}^{\text {реакц }}=\sum \Delta \mathrm{H}_{298}^{\circ}(\text { пр. })-\Delta \mathrm{H}_{298}^{\circ}(\text { исх. }), \\
& \Delta S_{298}^{\text {реакц }}=\sum S_{298}^{\circ}(\text { пр. })-S_{298}^{\circ}(\text { исх. }),
\end{aligned}
$$

a $\Delta \mathrm{H}_{298}^{\circ}$ - энтальпия образования каждого из участвующих веществ (пр. - продукты реакции, исх. исходные вещества) при $T=298 \mathrm{~K}, S_{298}^{\circ}$ - энтропия соответственно при $T=298 \mathrm{~K}$, причем

$$
\Delta G_{\text {реакц }}=-R T \ln K_{\rho},
$$

$R$ - универсальная газовая постоянная $\left(8,32 \frac{\text { Дж }}{\mathrm{K} \cdot \text { моль }}\right) \cdot$ 
Обоснованность написания уравнения процесса в виде (2) подтверждается расчетом равновесной степени диссоциации $\mathrm{Cl}_{2} \alpha$ по реакции

$$
\begin{gathered}
\mathrm{Cl}_{2} \text { (газ) } \leftrightarrow 2 \mathrm{Cl} \text { (газ), } \\
\mathrm{K}_{\rho}=4 \alpha^{2} P /\left(1-\alpha^{2}\right),
\end{gathered}
$$

причем

$$
\Delta G_{\text {реакц }}=242600-107,181 \cdot T \text { Дж/моль, }
$$

а справочные значения стандартных энтальпии и энтропии приведены ниже:

$\mathrm{TaCl}_{5}\left(\right.$ г): $\Delta \mathrm{H}_{\mathrm{f} 298}=-182,25$ ккал/моль [3];

$\Delta \mathrm{H}_{\mathrm{f} 298}=-182,4$ ккал/моль $=-763672$ Дж/моль [4];

$S_{298}=102,6$ кал/(моль $\cdot$ К) $=429,566$ Дж/(моль $\cdot$ К) [4];

Та (т): $S_{298}=9,92$ кал/моль;

$\mathrm{K}=41,533$ Дж/(моль $\cdot$ К) [4];

$\mathrm{Cl}\left(\right.$ г): $\Delta \mathrm{H}_{\mathrm{f} 298}=121302$ Дж/моль [5];

$S_{298}=165,076$ Дж/(моль $\cdot$ К) [5];

$\mathrm{Cl}_{2}$ (г): $S_{298}=222,965$ Дж/(моль $\left.\cdot \mathrm{K}\right)[5]$;

Результаты расчетов по уравнению (10) приведены на рис. 1.

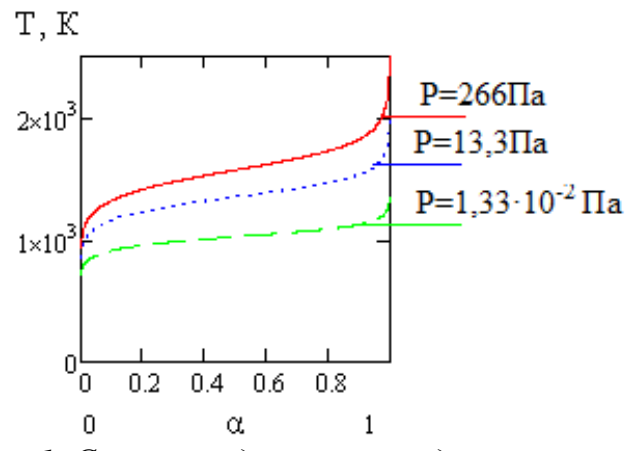

Рис. 1. Связь между степенью диссоџииации двухатомного хлора и температурой

Таким образом, в практически интересных интервалах температуры и давления величина $\alpha_{C l_{2}}$ близка к единице. Это позволяет обоснованно производить расчет равновесия процесса в соответствии с написанием уравнения реакции в виде (2), изменение свободной энергии которой с учетом вышеприведенных справочных данных равно:

$$
\Delta G_{\text {реакц }}=1470182-437,347 \cdot T \text { Дж/моль . }
$$

С учетом выражений (3), (8) и (12) рассчитываем зависимости температуры от степени превращения для давления $P=266 ; 13,3 ; 1,33 \cdot 10^{-2}$ Па соответственно (рис. 2).

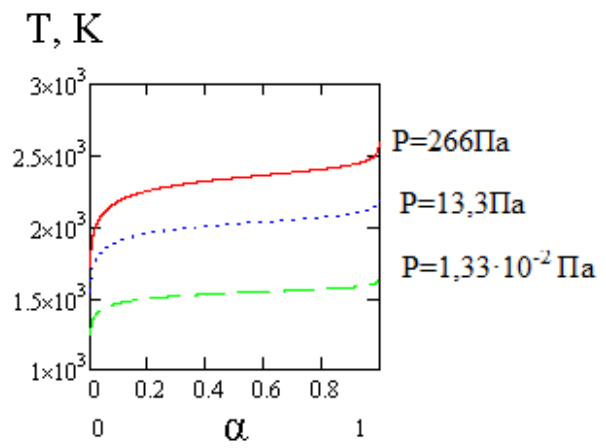

Pис. 2. Зависимости изменения температуры $T, K$ от степени превращчения $\alpha$ для реакциии (2) при значениях давления: 266; 13,3; 1,33 $10^{-2} \Pi а$
На рис. 3 приведены зависимости давления $P$ от степени превращения $\alpha$.

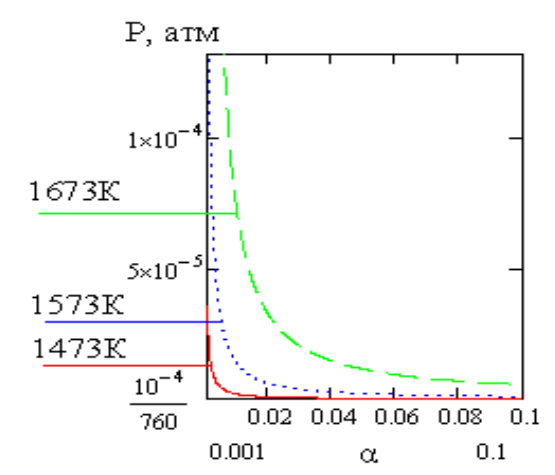

Pис. 3. Зависимости давления Р от степени превращения $\alpha$ по реакции (2) для температур: 1473, 1573 и $1673 \mathrm{~K}$

Зависимости температуры от давления для значений степени превращения $\alpha=0,1 ; 0,4$ и 0,7 приведены на рис. 4.

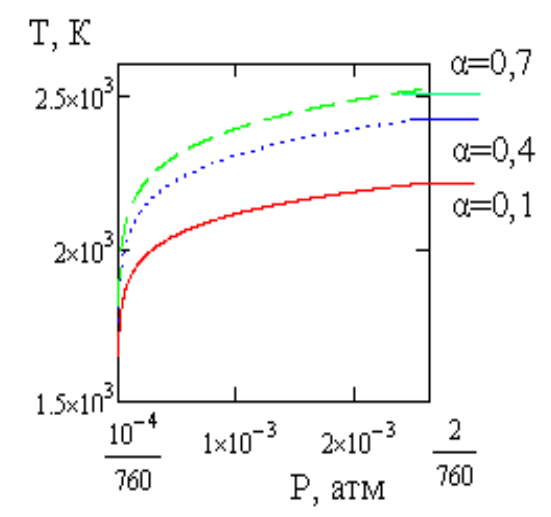

Рис. 4. Зависимости изменения температуры от давления для реакции (2), где кривые приведень для степени превращения $\alpha=0,1 ; 0,4$ и 0,7

Упругость пара $\mathrm{TaCl}_{5}$ в интервале $298-\mathrm{T}_{\text {пл }}$ в соответствии с уравнением [6]:

$\log P=-\frac{6275}{T}+34,305-7,04 \log T$ мм рт. ст.

графически показана на рис. 5.

$\mathrm{P}, \Pi \mathrm{a}$

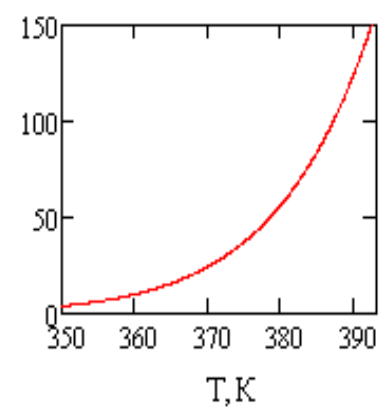

Рис. 5. Зависимость упругости пара пентахлорида тантала $\mathrm{TaCl}_{5}$ oт температуры

Совокупность вышеприведенных данных (см. рис. 1-5) позволяет перед проведением экспериментов по нанесению покрытий Та оценить необходимые параметры технологического процесса (интер- 
валы температуры осаждения и испарения пентахлорида тантала, давление в вакуумной камере).

\section{2. ЭКСПЕРИМЕНТАЛЬНОЕ ИССЛЕДО- ВАНИЕ ЗАВИСИМОСТИ СКОРОСТИ ОСАЖДЕНИЯ ТАНТАЛА ОТ ТЕМПЕРА- ТУРЫ И МАССОВОГО ПОТОКА ТаCl}

Эксперименты по осаждению тантала проводили в вакуумной установке при остаточном давлении атмосферного воздуха $1,33 \cdot 10^{-2}$ Па. В качестве подложек применяли образцы из танталовой жести толщиной 0,3 мм размером $50 \times 10$ мм. Это позволило исключить влияние отличного от тантала материала на процесс осаждения, поскольку пентахлорид тантала вступает в химическое взаимодействие практически с большинством материалов при температуре осаждения Та. Для нагрева образцов использовали водоохлаждаемый индуктор, выполненный из медной трубки $\varnothing 10 \times 1$ мм в виде плоской спирали Архимеда из шести витков. Этот индуктор нагружен на размещенный соосно с ним на расстоянии $\sim 5$ мм графитовый диск $\varnothing 100$ мм с вырезом в форме радиального сектора. На большом диаметре диска размещен покрываемый образец. Концы образца зажимали между двумя дисками (толщиной 4 мм каждый) из графита для создания электрического контакта, что позволяло замкнуть круговые токи, индуцированные в дисках, и тем самым обеспечить нагрев образцов (рис. 6). Электропитание индуктора производилось от высокочастотной установки ВЧИ-63-0,44, работающей на частоте 440 кГц.

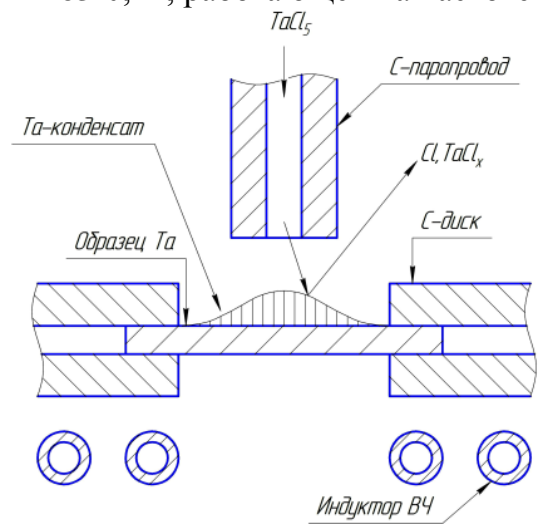

Рис. 6. Схема устройства для исследования методом CVD прочесса осаждения Ta из $\mathrm{TaCl}_{5}$

Перпендикулярно центральной части плоскости образцов располагали на расстоянии 5 мм графитовую трубку-паропровод с отверстием $\varnothing 4$ мм на ее торце для истечения паров пентахлорида тантала. Пары пентахлорида тантала поступали по паропроводу из съемного испарителя. Его поддерживали с заданной температурой в диапазоне $360 \ldots 390 \mathrm{~K}$ с точностью $\pm 0,5 \mathrm{~K}$, которая задавалась контактным термометром типа ТРК с электронным ключом. Изменение массового потока паров пентахлорида тантала к поверхности подложки и тем самым регулирование эффективного давления в зоне осаждения покрытия достигали путем изменения температуры испарителя. Количество испаренного за время $\Delta t$ пентахлорида тантала устанавливали взвешиванием испарителя при закрытом его затворе до и после проведения эксперимента на весах BTU-2100. В этом случае испаритель отсоединяли от вакуумной камеры, используя разъемное вакуумное соединение. В процессе эксперимента температуру образца контролировали оптическим пирометром типа «Промінь» и регулировали изменением подводимой к индуктору мощности высокочастотного излучения от генератора ВЧИ-63-0,44. Количество осажденного за время $\Delta t$ конденсата тантала определяли путем взвешивания образца до и после эксперимента на весах типа ВЛР-20. Толщину покрытия измеряли микрометром по разности данных до и после осаждения, а также на микрошлифах.

На рис. 7 приведены данные зависимости экспериментального коэффициента использования пентахлорида тантала $\alpha_{\text {эксп }}$ от температуры подложки, пропорционального скорости осаждения покрытия в

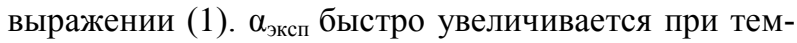
пературе выше $1470 \mathrm{~K}$ до достижения насыщения при $\sim 1820 \mathrm{~K}$.

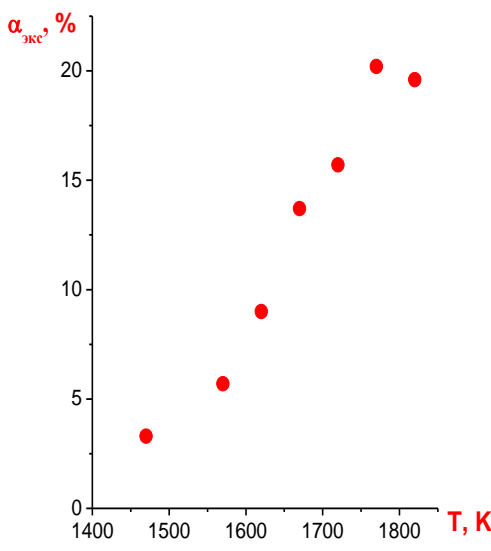

Рис. 7. Экспериментальная зависимость выхода Та из $\mathrm{TaCl}_{5}$ в покрытие от температуры подложки

Величина $\alpha_{\text {экп }}$ не достигает расчетного равновесного значения $\alpha$ вследствие наличия коэффициента $\beta<1$ в выражении (1), зависящего от геометрии используемого реактора и указывающего на степень непроизводительного рассеяния в вакуум пентахлорида тантала, который не участвует в процессе конденсации покрытия в равновесных условиях. Данные рис. 7 относятся к величине 5 г/ч массового потока пентахлорида тантала.

На рис. 8 приведены зависимости $\alpha_{\text {эксп }}(\square)$ и соответствующей скорости осаждения покрытия $V(+)$ в выражении (1) от массового потока пентахлорида тантала. Данные соответствуют проведению процесса при температуре подложки 1720 К (см. рис. 8).

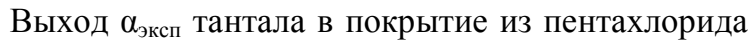
тантала уменьшается с $\approx 17$ до $\approx 10 \%$ при увеличении массового потока пентахлорида с $\approx 3$ до $\approx 11$ г/ч. Это соответствует принципу Ле-Шателье, согласно которому увеличение эффективного давления должно подавлять выход Та по реакции с увеличением числа частиц в газовой фазе. 


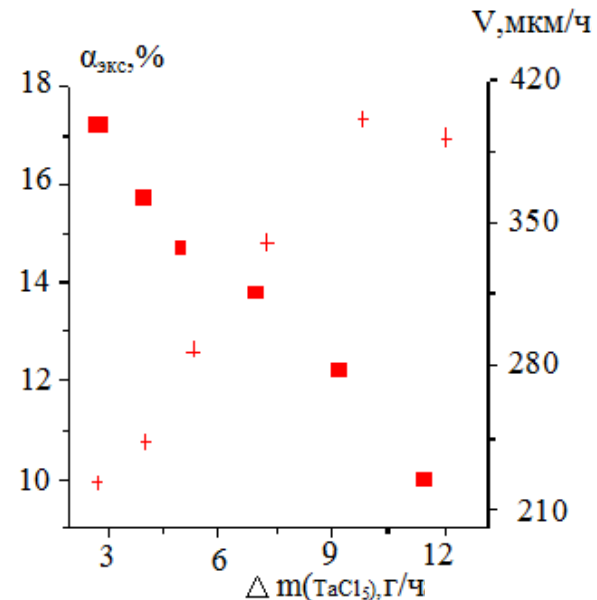

Рис. 8. Экспериментальная зависимость выхода Та из $\mathrm{TaCl}_{5}$ в покрытие от массового потока $\mathrm{TaCl}_{5}($ ( )

и скорость роста покрытия от массового потока паров $\mathrm{TaCl}_{5}(+)$.

Все данные получены при температуре $1720 \mathrm{~K}$

Таким образом, увеличение эффективного давления $P$ пентахлорида тантала вблизи поверхности подложки, обусловленное ростом величины $\frac{\Delta m_{\mathrm{TaCl}}}{\Delta t}$ в выражении (1), приводит к уменьшению равновесного выхода $\alpha$ по рассматриваемой реакции.

Тем не менее при уменьшении $\alpha$ скорость осаждения $V$ увеличивается (при заданной температуpe), поскольку растет величина массового потока пентахлорида тантала, входящего в соотношение (1) в качестве линейного множителя.

Практически при разработке технологии нанесения покрытий тантала на конкретные изделия необходимые расход пентахлорида и скорость осаждения тантала следует выбирать, учитывая характер экспериментальных зависимостей, приведенных на рис. 8. Это позволит как экономно расходовать дорогостоящий пентахлорид тантала, так и оптимизировать температурный режим проведения процесса и соответственно регулировать финишные свойства покрытий, которые и определяют их эксплуатационную эффективность и ресурс.

\section{ВЫВОДЫ}

1. Исследовано влияние температуры подложки и давления на процесс термической диссоциации паров пентахлорида тантала на нагретой в интервале $1470 \ldots 1820$ К поверхности, и проведено сравнение расчетных термодинамических равновесных данных с экспериментальными.

2. Скорость нанесения покрытий из тантала возрастает с увеличением массового потока паров его пентахлорида; при этом коэффициент использования пентахлорида тантала убывает, т. е. растут его непроизводительные потери вследствие рассеяния паров внутри вакуумной камеры.

Экономия дорогостоящего пентахлорида тантала может быть достигнута выбором оптимальных параметров процесса на основе данных настоящей работы.

\section{БИБЛИОГРАФИЧЕСКИЙ СПИСОК}

1. Осаждение из газовой фазы / Под ред. К. Пауэлла, Дж. Оксли и Дж. Блочера мл. / Пер. с англ. М.: «Атомиздат», 1970, $472 \mathrm{c}$.

2. Ю.И. Поляков, Г.Н. Картмазов, Ю.В. Лукирский и др. Кинетика пиролиза летучих соединений металлов при нанесении покрытий в вакууме // Boпросы атомной науки и техники. Серия «Физика радиационных повреждений и радиаиионное материаловедение». 2011, №2(72), с. 163-167.

3. Термические константы веществ / Под ред. В.П. Глушко. М.: ВИНИТИ АН СССР, 1968, в. 3; 1970 , в. 4 , ч. $1 ; 1971$, ч. $2 ; 1974$, в.7, ч. $1,2$.

4. О. Кубашевский, С.Б. Олкокк. Металлургическая термохимия. М., 1982, 392 с.

5. Термодинамические свойства индивидуальных веществ / Под ред. В.П. Глушко. М.: «Наука», 1978, T. 1-4.

6. К.Дж. Смитлз. Металль: Справ. изд. / Пер. с англ. $1980,447 \mathrm{c}$.

Статья поступила в редакичию 06.03.2019 2.

\title{
ДОСЛІДЖЕННЯ ПРОЦЕСУ ТЕРМІЧНОЇ ДИСОЦІАЦЇ ПЕНТАХЛОРИДУ ТАНТАЛУ У ВУКУУМІ
}

\section{Ю.І. Поляков, С.Г. Руденький, Ю.В. Лукирський, І.І. Коновалов, В.І. Рак}

У рамках рівноважної хімічної термодинаміки отримана залежність ступеня дисоціації парів $\mathrm{TaCl}_{5}$ $\alpha(T, P)$ від температури в інтервалі $1470 \ldots 1820 \mathrm{~K}$ і вакуумі $1,33 \cdot 10^{-2}$ Па. Проаналізовано та порівняно з розрахунковими експериментальні дані залежності $\alpha_{\text {експ }}(T, P)$ від температури і масового потоку парів $\mathrm{TaCl}_{5}$.

\section{STUDY OF THE PROCESS OF THERMAL DISSOCIATION OF TANTAL PENTACHLORIDE IN VACUUM}

\author{
Yu.I. Polyakov, S.G. Rudenkyi, Yu.V. Lukirsky, I.I. Konovalov, V.I. Rak
}

The dependence of the degree of dissociation of $\operatorname{TaCl}_{5} \alpha(T, P)$ vapors on the temperature in the range of $1470 \ldots 1820 \mathrm{~K}$ in a vacuum of $1.33 \cdot 10^{-2} \mathrm{~Pa}$ was by using of equilibrium chemical thermodynamics obtained. The experimental data on the dependence of $\alpha_{\mathrm{ex}}(T, P)$ on temperature and vapor mass flow $\mathrm{TaCl}_{5}$ were analyzed and compared with calculations. 